\title{
Experiências de planos de bairro no Nordeste brasileiro: articulando planejamento insurgente e direito à cidade
}

\author{
Neighborhood planning experiences in Northeast Brazil: \\ articulating insurgent planning and the right to the city
}

Thaís de Miranda Rebouças [l] Maya Manzi [II]

Laila Nazem Mourad [III]

\section{Resumo}

Este artigo analisa duas experiências recentes de planejamento insurgente na escala do bairro no Nordeste do Brasil, que emergem em um contexto urbano caracterizado pela perda progressiva de direitos por seus habitantes e pela sua retomada a partir de práticas alternativas de planejamento. 0 artigo discute a conformação de diversas relações entre Estado, universidade e comunidades, os tipos de conhecimento e de linguagem usados, bem como as possibilidades de transformação social que o planejamento insurgente propicia enquanto processo reativo e construtivo. Os resultados mostram que a luta pelo direito à cidade se constitui como parte integrante do caráter insurgente dos Planos de Bairro no Nordeste do Brasil, uma contribuição para a teorização do planejamento desde/para o Sul global.

Palavras-chave: plano de bairro; planejamento insurgente; direito à cidade; neoliberalismo; Brasil.

\begin{abstract}
This paper analyzes recent experiences of insurgent planning on the neighborhood scale in the Northeast region of Brazil. These experiences have emerged in an urban context characterized by its inhabitants' progressive loss of rights and by the resumption of these rights through alternative planning practices. The paper discusses the configuration of different relations between the State, the university and communities, types of knowledge and languages used, and the possibility of social change that insurgent planning enables as a reactive and constructive process. The results show that the struggle for the right to the city is an integral part of the insurgent character of the Neighborhood Plans in Northeast Brazil, a contribution to the planning theory from/for the Global South.
\end{abstract}

Keywords: neighborhood planning, insurgent planning, right to the city, neoliberalism, Brazil. 


\section{Introdução}

0 planejamento urbano, do modo como é realizado hoje no Brasil, de cima para baixo, é incapaz de incorporar os conflitos inerentes à sociedade e as disputas entre seus diferentes agentes, o que, conforme Maricato (2011), é uma característica da sociedade brasileira, que "tem tradição de ignorar, ou melhor, não reconhecer a existência de conflitos sociais" (p. 71). Os conflitos existentes na sociedade, em geral, não aparecem nos planos diretores, que costumam trabalhar com cenários lineares e pacíficos.

As soluções para os problemas urbanos formulados por urbanistas naufragam, entre outras razões, por um processo de formulação não compartilhado com a sociedade. Também contribui para o descrédito inerente à prática do planejamento urbano no Brasil a generalizada incapacidade de implementar os planos produzidos, dentre os quais destacamos os planos diretores. Villaça (2005) aponta para a distância existente entre o discurso e a prática, observada na história do planejamento urbano brasileiro, o que contribuiu para gerar uma ilusão, que, segundo o autor, "decorre do abismo que separa o seu discurso da prática de nossa administração municipal e da desigualdade que caracteriza nossa realidade política e econômica" (p. 90).

No nosso entendimento, o planejamento de bairro possibilita, sobretudo, o enfrentamento técnico e político dos conflitos que se deflagram no lugar. Esse é um processo que Vainer et al. (2013) chamam de Planejamento Conflitual, que "aposta na capacidade dos processos conflituosos de constituírem sujeitos coletivos aptos a ocuparem, de forma autônoma, a cena pública" (p. 17). Aqui, o planejamento urbano, tão criticado pelo seu peso ideológico e ineficácia, passa a ser utilizado como ferramenta para enfrentar os conflitos.

Algumas experiências de elaboração de planos de bairro se tornaram referência no País. Uma experiência embrionária destacada por Mourad (2012), em seu relatório técnico sobre o levantamento bibliográfico analítico direcionado ao entendimento de como a questão do bairro ou planos de bairros foi problematizada no planejamento no Brasil, aponta os trabalhos do padre Lebret com a Sociedade para Análises Gráficas e Mecanográficas Aplicadas aos Complexos Sociais - Sagmacs -, em 1947, como os primeiros registros de análise e planejamento urbano na escala do bairro no Brasil. Segundo Mourad (ibid.), os estudos de Lebret trazem para o centro do debate a questão social, analisando os níveis de vida das classes trabalhadoras na escala de seus habitats. Segundo essa autora, "as concepções e as práticas introduzidas por Lebret se referem a uma metodologia de pesquisa da realidade urbana que vincula 0 pensamento urbanístico à ação política" (ibid. p. 2), o que, naquela época, constituía um grande avanço no campo da teoria e da prática do planejamento urbano. Também na década de 1950 é possível destacar o Plano de Brasília (Fernandes, 2011), que trabalha com a unidade de vizinhança nos termos de escala e distribuição de serviços e equipamentos urbanos no espaço.

Na década de 1970, um grande marco no campo do planejamento de bairro no Brasil e uma grande referência de experiência participativa nesse sentido foi o bairro do Catumbi, na área central do Rio de Janeiro, que sofria ameaça de erradicação por um plano 
de renovação urbana do poder público já em 1964. 0 bairro, conhecido pela sua ocupação por uma população originalmente imigrante, era classificado pelo poder público como de qualidades urbanísticas indesejáveis, discurso que justificava sua atuação na área. Na década de 1970, o bairro sofre mais pressões do poder público e do mercado imobiliário, com a construção de um viaduto e de um túnel que o ligavam à Área Central de Negócios, uma das mais valorizadas do Rio de Janeiro.

0 trabalho de Santos (1985) tomava o bairro como uma "unidade espacial e ideológica", e seu foco de abordagem foi a apropriação das áreas de uso coletivo e de lazer. Apesar da luta dos seus moradores e do trabalho realizado por Santos no bairro, suas reivindicações não foram ouvidas e muitos moradores foram removidos. Nesse mesmo período, é possível observar diversas iniciativas de elaboração de planos de bairro no Rio de Janeiro e em Salvador (Rebouças e Silva, 2015), mas, é a partir dos anos 2000, que surgem diversos planos de bairro que são demandados e elaborados por seus moradores. Alguns deles, como o Plano Popular da Vila Autódromo (2012) e o Plano de Bairro da Vila Pompéia (2013), ganham notoriedade nacional e são tomados como referências metodológicas e de luta por diversas iniciativas realizadas nos anos 2010.

Neste artigo, analisam-se duas experiências contemporâneas de planejamento urbano na escala do bairro no Nordeste do Brasil: o Plano de Bairro 2 de Julho, ${ }^{1}$ em Salvador (BA), e o Plano de Bairro de Casa Amarela, ${ }^{2}$ em Recife (PE). Qualificamos essas experiências como insurgentes, pois elas emergem da mobilização dos próprios habitantes desses bairros, que vêm contestando as práticas urbanas neoliberais do estado empresarial e propõem novas formas de pensar e produzir a cidade. A análise desses casos ajuda a entender o contexto político, social e urbano no qual o planejamento insurgente no Nordeste do Brasil emerge, a complexidade das relações que se estabelecem entre diversos agentes e subjetividades e entre diversos tipos de conhecimento e de linguagem, com suas tensões, ambiguidades e implicações em termos de possibilidade de transformação social. Os casos revelam a importância de pensar o direito à cidade e o planejamento insurgente de forma articulada e situada. Assim, 0 artigo também acrescenta, à literatura engajada em decolonizar e "internacionalizar", a teoria do planejamento (Watson, 2014, p. 24) a partir de uma perspectiva situada desde o Sul global (Miraftab, 2009; Yiftachel, 2006; Watson, 2014).

Assim, se entendemos o planejamento como a projeção e a problematização do futuro, ancoradas em objetivos, finalidades e em perspectivas de futuro e de transformação do meio (Santos, 2004) e como uma ação que tem como objetivo o governo sobre os homens e sobre suas ações (Foucault, 1995), entendemos que o plano de bairro deve conter mais que estudos (detalhados ou não) sobre a realidade do lugar, mas também o esforço de construção de perspectivas de mudança na configuração e na gestão do espaço e das pessoas, perspectivas de indivíduos e grupos que se disponham a colaborar para transformação do meio e da realidade existente, assim como com permanências futuras. 0 plano de bairro, tal como praticado nas experiências do 2 de Julho e de Casa Amarela, inscreve-se na necessidade de alargamento da concepção de planejamento descrita por Miraftab (2016), incluindo ações que não envolvem planejadores 
convencionais - ações coletivas libertadoras, práticas oposicionistas de base que inovam e criam seus próprios termos de engajamento, isto é, formas de expressão e de inclusão autodeterminadas "nas quais os direitos das pessoas são reais e praticados" (p. 368).

Nesse viés, 0 artigo estrutura-se em seis partes: a primeira, a introdução, contextualiza o debate sobre a tradição do planejamento urbano no Brasil de não reconhecer a existência de conflitos sociais, apresentando também algumas experiências de elaboração de planos de bairro que se tornaram referência no País, desde a década de 1950, e anunciam-se duas práticas contemporâneas de planejamento insurgente na escala do bairro no Nordeste do Brasil que emergem da potência dos conflitos.

Na segunda parte, trata-se do planejamento urbano e de seus contornos neoliberais, em que a cidade neoliberal do século XXI é regulada pelos marcos da governança corporativa e voltada para a atração de investimentos privados, não havendo lugar para grupos historicamente marginalizados. No Nordeste do Brasil, a neoliberalização da cidade afeta a população negra de maneira particularmente violenta. A lógica neoliberal produz novas formas de relação entre o Estado e o capital fundiário-imobiliário, alterando completamente o sentido público das funções da cidade, tornando-a cada vez mais o reflexo dos interesses privados de empresariamento do território urbano. Em seguida, apresentam-se teorizações sobre planejamento "radical" (Friedmann, 1987; Beard, 2003), "insurgente" (Sandercock, 1999; Miraftab, 2009), "subversivo" (Randolph, 2007), e "conflitual" (Vainer et al., 2013), na tentativa de informar teoricamente as duas experiências analisadas, tomando em consideração as contribuições das perspectivas críticas do Norte e Sul global sobre o planejamento urbano contra-hegemônico.

Segue-se, com a apresentação teórica da noção do direito à cidade, entendida na perspectiva mais radical de Henry Lefebvre e seus seguidores. Na quinta parte, apresentam-se 0 Plano de Bairro 2 de Julho, em Salvador (BA), e o Plano de Bairro Casa Amarela, em Recife (PE), como exemplos de práticas contemporâneas de planejamento insurgente na escala do bairro. Ambas as práticas emergem em contexto de conflito, desenvolvem-se fora dos espaços institucionais do Estado, apesar de circularem por eles, inserem-se na perspectiva de construção de possibilidades futuras baseadas em práticas emancipatórias e reivindicam exercer o direito de decidir sobre seus espaços.

Por fim, na sexta parte, argumenta-se a necessidade de entender o planejamento insurgente a partir do direito à cidade (e vice-versa). Refletindo sobre a crítica à banalização do direito à cidade, sugere-se que essa articulação conceitual contribui tanto para recuperar 0 sentido mais radical da noção de direito à cidade, quanto para ampliar e trazer complexidade à teorização sobre planejamento insurgente uma contribuição teórica desde o Sul global.

\section{Planejamento urbano e seus contornos neoliberais}

A prática de planejamento, especialmente na sua vertente neoliberal, organiza as estratégias econômicas e territoriais de desenvolvimento urbano e, na maioria dos casos, estabelece as possibilidades de lucro dos empreendimentos 
imobiliários (com a definição dos gabaritos e coeficientes de aproveitamento dos terrenos, por exemplo). Fernandes (2013), citando Harvey (2014), destaca que historicamente a urbanização tem se apresentado como uma das estratégias centrais de acumulação de capital e aponta, ainda, uma crescente tendência de expansão das cidades por sobreposição ou densificação de determinadas áreas da cidade. Muitas dessas áreas não são ocupadas justamente visando à incorporação da mais-valia gerada por investimentos públicos através da especulação imobiliária.

Por um lado, o planejamento institucionalizado pelo Estado, baseado em políticas de controle do uso da terra e em instrumentos de política urbana como forma de captura e transferência de renda para os mais ricos, alija a população mais vulnerabilizada de possibilidades de acesso ao direito à cidade. Por outro, as grandes corporações, em especial as imobiliárias, figuram como agentes centrais do processo de planejamento das cidades, vendo-as como mercadorias e oportunidades para negócios. Elas descobriram nas cidades terrenos férteis para seus investimentos e têm se empenhado fortemente em interferir nas suas normas e nas estratégias para o seu desenvolvimento.

Esse é o motivo pelo qual Fernandes afirma que "o campo de ação corporativa é urbano, mas é também urbanístico" (2013, p. 88). Com isso, a autora ressalta que a atuação das corporações passou a extrapolar o mero uso e apropriação (privada) do espaço urbano e de sua renda imobiliária, por meio da atuação direta na produção de grandes extensões urbanas. Assim, a definição da ordem urbanística entra na agenda das corporações imobiliárias como ação estratégica de ampliação de investimentos.
Considerando-se o papel do planejamento urbano como instrumento definidor de investimentos públicos e privados nas cidades e sua crescente disputa por parte de corporações e mesmo médios investidores imobiliários, fica claro que esse é um campo de relações de poder que merece ser disputado.

0 que não se pode perder de vista é 0 campo mais ou menos aberto de possibilidades de ação dentro desse dispositivo de poder que é o planejamento urbano. É um campo estratégico de disputa por diversos agentes atuantes nas cidades, não apenas as corporações imobiliárias. Disputar esse campo e reagir conscientemente ante o exercício de poder sobre si e sobre os outros são ações fundamentais para dar visibilidade a essas relações e causar-lhes instabilidade.

Nesse sentido, se assumimos que 0 instrumento do planejamento urbano tem a prerrogativa de limitar e/ou potencializar possibilidades de desenvolvimento dos meios urbanos, ele exige para si - também - a intenção e a capacidade de interferir no processo de produção social do espaço, e esse é o olhar que teremos sobre os processos que serão aqui apresentados. Embora a maioria dos moradores proponentes e/ou executores da elaboração de planos de bairro não possua essa perspectiva elaborada, a disputa pela produção social do espaço nos bairros é, neste trabalho, uma questão central, assim como também o é para seus moradores. Nas grandes cidades, o planejamento urbano apresenta-se como uma estratégia de ação do Estado e também do capital imobiliário. Interessa aqui, então, investigar até que ponto ou em que medida ele também pode ser utilizado como uma estratégia dos habitantes/ citadinos na produção do seu próprio espaço. 
0 planejamento insurgente tem emergido principalmente nas periferias do Norte e Sul globais, e, particularmente, em lugares onde 0 legado do colonialismo e seu entrelaçamento com regimes ultraneoliberais têm produzido efeitos perversos nas cidades e nas populações historicamente marginalizadas (negros, indígenas, mulheres, LGBTs, etc.). Esses efeitos se manifestam material e espacialmente através de processos de gentrificação e higienização que resultam na despossessão, exclusão, segregação e periferização desses segmentos. Por isso, o debate sobre planejamento urbano requer a interpretação crítica da realidade, mostrando que aquelas modificações que estão se processando na cidade ameaçam grupos sociais específicos.

É em contraposição a essa lógica que práticas contra-hegemônicas vêm sendo concebidas através de formas alternativas de planejamento que se inserem na perspectiva de construção de possibilidades futuras baseadas em práticas emancipatórias.

\section{Teorias sobre planejamento contra-hegemônico}

Dentro da literatura de planejamento urbano, modos de planejamento contra-hegemônicos são originários de movimentos sociais, de profissionais e acadêmicos que têm um engajamento com a ação social e que vêm experienciando, em seus processos históricos, 0 planejamento como instrumento na luta por cidades mais justas. 0 debate sobre o planejamento contra-hegemônico insere-se em contexto de crise global do capitalismo, bem como do planejamento como profissão e como ideia. Nesse sentido, portanto, a "necessidade de outras práticas de planejamento, de um novo significado e uma nova imaginação" (Miraftab, 2016, p. 1).

0 planejamento alternativo centra-se nas comunidades marginalizadas e/ou desfavorecidas, nos conflitos sociais, nas lutas e nas resistências contra remoções, e sua prática vem se desdobrando e se imbricando na construção de alguns conceitos, como planejamento "subversivo" (Randolph, 2007), "conflitual" (Vainer et al., 2013), "radical" (Friedmann, 1987; Beard, 2003) e "insurgente" (Sandercock, 1999; Miraftab, 2009, 2016). Essas construções merecem destaque por se tratarem, em sua maioria, de elaborações a partir de reflexões sobre práticas e experiências com origens no Sul global.

0 planejamento subversivo constitui-se de práticas que invertem ou subvertem as "relações tanto entre Estado e sociedade em geral, como entre planejadores e a população envolvida e afetada" (Randolph, 2007, p. 13). Para Randolph (ibid.), um planejamento subversivo "precisa criar o espaço tempo necessário para a valorização da experiência (e vivência) social". Essa prática "decorre de uma determinada compreensão do mundo contemporâneo e de uma profunda preocupação de buscar direções de sua transformação". Ampara-se no que ele chama de "força criativa que vem da práxis" e propõe uma nova "dimensão de mediação" (ibid., p. 11) do planejamento urbano com a compreensão e o propósito de tensionamento da produção do espaço social, nos termos colocados por Lefebvre (2013) no seu livro $A$ produção do espaço.

A inversão e/ou subversão das relações de poder na prática do planejamento implica 
não apenas desvelar os conflitos presentes na realidade em questão, mas incorporá-los ao processo mesmo de planejar. Uma importante contribuição nesse sentido - e ainda em desenvolvimento - é a ideia de planejamento conflitual, em que Vainer et al. (2013) alertam para o perigo do banimento do conflito nas práticas institucionalizadas do planejamento. Em contraposição a essa prática, o conflito assume grande importância, justamente por suas possibilidades de criação e de construção dos agentes nele envolvidos.

Já o planejamento "insurgente" e/ou "radical" provém de uma tradição anterior das abordagens críticas ao planejamento, formulado inicialmente por Friedmann (1987) e depois desenvolvido por Sandercock (1999), Beard (2003) e Miraftab $(2009,2016)$, entre outros autores que deslocaram o planejamento urbano a partir das práticas cidadãs como formas de planejamento contestatório.

Friedmann (1987) traz a contribuição ao debate sobre planejamento radical, compreendido como a mediação entre teoria e prática para a transformação social. Esse tipo de planejamento seria o resultado de mobilizações sociais emancipatórias com ampla participação social nas quais o planejador assume menos o papel de quem organiza e conduz o processo, sendo integrado mais como militante no coletivo político que as efetiva. Nessa lógica, o planejamento radical buscaria emancipar a humanidade da opressão social e das desigualdades geradas pelo Estado e pelo mercado (Beard, 2003).

Sandercock (1999) enfatiza a dimensão antagonística do planejamento insurgente que visa a desestabilizar a versão modernista ou meramente reformista do planejamento estatal. Segundo ela, o planejamento é insurgente pela virtude de desafiar relações de poder existentes de alguma maneira. Portanto, vai além da "participação" em um projeto definido pelo Estado. Opera dentro de configurações de poderes políticos e formula estratégias de ação. As práticas de planejamento insurgente podem ser histórias de resistências nem sempre exitosas [...] de resiliência [...] ou de reconstrução. (Sandercock, 1999, p. 41 apud Sweet e Chackars, 2010, p. 20; tradução nossa)

A partir dessas formulações iniciais, a ideia de planejamento insurgente tem adquirido um apelo cada vez maior como instrumento analítico, teórico e metodológico que permite dar conta de experiências de planejamento contra-hegemônico que, muitas vezes, são silenciadas, ignoradas ou boicotadas pelo Estado, por representarem uma ameaça ao status quo. Nesse contexto, Miraftab (2009) entende o planejamento insurgente como planejamento radical que contesta a inadequação do planejamento participativo performado pelo Estado neoliberal, cuja narrativa de "inclusão social" tem servido mais a legitimar os interesses do mercado do que atender às necessidades e garantir os direitos dos habitantes da cidade. As práticas de planejamento insurgente, segundo Miraftab (ibid.), podem ser caracterizadas como: (1) "contra-hegemônicas", por desestabilizarem a ordem vigente normalizada; (2) "transgressivas", por colocarem a memória histórica e a consciência transnacional no centro das suas práticas; e (3) "imaginativas", por acreditarem que um outro mundo é possível e necessário (p. 33).

Como apontado por Beard (2003), a maioria dos casos de planejamento insurgente/radical tem ocorrido em comunidades locais. Porém, esse tipo de planejamento 
também pode operar em outras escalas, como metropolitanas, regionais, nacionais ou internacionais. É essa possibilidade de o planejamento radical operar em várias escalas e esferas que o torna mais propenso a efetivar mudanças estruturais.

Alguns autores têm questionado o conceito de planejamento radical ou insurgente, por reforçar uma concepção dicotômica da relação Estado-sociedade. Apesar da performatividade do planejamento insurgente colocar-se como "fora" ou "contra" o Estado, essa dicotomia é ilusória, já que a insurgência existe como reação a um Estado opressor, e esse Estado se mantém precisamente pela existência de uma cidadania diferenciada e subalterna (Holston, 2013). Ou seja, lembrando Gramsci, Estado e sociedade, assim como planejamento hegemônico e insurgente, constituem-se mutuamente. É por isso que o planejamento insurgente, mesmo se definindo pela sua oposição ao Estado hegemônico, nunca se localiza completamente fora dele. Isto se denota no uso de táticas que navegam de maneira fluida entre a formalidade e a informalidade, entre as instituições e as ruas, entre a legalidade e a ilegalidade, o que Miraftab (2009) distingue analiticamente em: "espaços convidados" de participação cidadã sancionados pelas autoridades e "espaços inventados", espaços de contestação política, nos quais se criam e fortalecem movimentos contra-hegemônicos.

As práticas de cidadania e planejamento insurgentes no Brasil são emblemáticas de como os limites entre essas categorias não são tão nítidos. Por exemplo, no seu estudo sobre a União dos Movimentos de Moradia em São Paulo, Earle (2012) mostra como a ocupação de imóveis vazios pelos "sem teto" constitui-se como "cidadania transgressiva", embora sua tática central seja aderir aos textos constitucionais e responsabilizar o Estado por eles. Esse tipo de cidadania insurgente é centrado tanto na ilegalidade quanto na legalidade, já que, de um lado, infringe a lei civil (invasão de propriedade privada) e, de outro, usa as leis urbanas para garantir o direito à moradia, a partir da constituição de 1988 e de outros instrumentos legais que exigem que as propriedades privadas e a cidade como um todo cumpram as suas funções sociais.

Autores como Beard (2003) e Irazábal e Nevile (2007) também têm estudado como o planejamento radical enquanto oposição ao Estado não se manifesta sempre de forma explícita, particularmente dentro de contextos políticos repressivos e autoritários. Esse tipo de planejamento, chamado de planejamento encoberto (covert planning), refere-se a uma estratégia consciente de uma comunidade de disfarçar suas táticas insurgentes de planejamento no intuito de evitar possíveis represálias do poder vigente.

Para Beard (2003), a relação Estado-sociedade no planejamento radical pode ser melhor entendida quando examinada de forma longitudinal. No seu estudo sobre ações coletivas em assentamentos urbanos precários na Indonésia, a autora examina o processo de aprendizagem que leva os moradores ao planejamento radical em contextos políticos autoritários. Argumenta que esse processo é progressivo e que tende a iniciar-se com ações participativas convencionais, promovidas pelo Estado, para, posteriormente, desdobrar-se em ações cada vez mais autônomas e radicais, uma vez que a comunidade acumula experiência e cria novas formas de organização. 
No seu estudo sobre as práticas insurgentes de mulheres na África do Sul, Meth (2010) questiona a tendência de se conceberem práticas insurgentes como necessariamente transformadoras e progressivas. Ela mostra, ao contrário, como as práticas insurgentes de vigilância das mulheres, em dois bairros da cidade de Durban, para solucionar o problema de agressão dos homens contra as mulheres tornam-se repressivas, violentas e, às vezes, injustas. Numa linha semelhante, Latendresse e Manzi (2018) mostram como o planejamento insurgente nos bairros de Pointe Saint-Charles, em Montreal, e no 2 de Julho, em Salvador, por serem inclusivos no seus processos de elaboração coletiva, acabam refletindo eventualmente a cultura política hegemônica do Estado, com propostas de ações conservadoras que podem contribuir para a reprodução de espaços urbanos excludentes e violentos, como no caso de propostas para aumentar a presença policial no bairro como forma de solucionar 0 alto nível de criminalidade. Esses estudos mostram que tanto o Estado quanto as comunidades podem engendrar planejamentos insurgentes emancipatórios ou repressivos.

Como veremos adiante, os planos de bairro elaborados com participação ativa e coletiva da população residente representam uma forma de planejamento insurgente que se caracteriza por ocupar essa posição ambígua entre uma relação de dependência e de autonomia, de subordinação e de oposição, de cooperação e de conflito perante o Estado ou outras instituições envolvidas, mas também por serem práticas promovidas por uma multiplicidade de subjetividades, instrumentos, linguagens e finalidades que tencionam seu caráter subversivo.

Assim, o plano de bairro enquanto planejamento insurgente tem o potencial de desestabilizar, mas também de estabilizar, a relação entre Estado e sociedade. Ele não é subversivo na sua essência, nem um fim em si mesmo, mas um processo de construção coletiva contínuo, enraizado no cotidiano e atravessado por várias escalas e esferas de relações e organizações. Portanto, é preciso entender melhor quais são as condições, os contextos e os processos que moldam o caráter transformativo do planejamento insurgente. Para isso, seguindo Beard (2003), investigamos os processos formativos dos planejadores insurgentes, particularmente no que diz respeito à linguagem do direito à cidade e à sua mobilização para servir aos interesses da população citadina.

Tanto o planejamento radical como o insurgente colocam em pauta - ainda que não explicitamente - um direito reivindicado, ainda na década de 1960, por Lefebvre (2008), que é o direito à cidade, que trata justamente da possibilidade - e necessidade - da participação na produção social do espaço e da sua apropriação. Seu propósito radical e revolucionário - pois requer a inversão do processo de dominação na produção do espaço - recebe contribuições importantes das teorias de planejamento abordadas neste artigo e, embora seus autores não tenham estabelecido esse diálogo, juntos se reforçam e impulsionam o caldo teórico da construção do espaço urbano a partir de ações insurgentes. 


\section{0 direito à cidade como prática radical e revolucionária}

Na década de 1960, Lefebvre cunhou o termo "direito à cidade", que afirmou se tratar de uma "forma superior dos direitos", constituindo-se no "direito à liberdade, à individualização na socialização, ao habitat e ao habitar" (Lefebvre, 2008, p, 134). Tratava-se de um direito revolucionário por princípio, pois nele estavam implicados "o direito à obra (à atividade participante) e o direito à apropriação (bem distinto do direito à propriedade)" (ibid., p. 134; grifos nossos).

Esse direito à atividade participante a que se refere Lefebvre consiste na participação nos processos de tomadas de decisão sobre a sociedade e sobre a elaboração e construção das suas realidades. A obra, para Lefebvre, contrapõe-se ao produto, sendo este último resultado da produção capitalista, das relações de propriedade do solo; e o espaço sob a égide das relações capitalistas é aquele cuja finalidade primeira é o lucro e o consumo (ibid.). A obra, por sua vez, refere-se mais ao trabalho do que propriamente à obra de arte, pois não possui um objetivo preestabelecido e uma finalidade clara no momento da sua concepção (ibid.). A cidade como obra seria a centralidade do espaço social, fruto do trabalho e das decisões coletivas sobre sua produção, tendo a apropriação como o oposto à propriedade.

Segundo Purcell (2002, p. 102), esse direito à participação significa que os "citadinos deveriam jogar um papel central em qualquer decisão que contribua para a produção do espaço urbano"; sendo essa decisão tomada seja pelo Estado, seja por entidades e/ou empresas, considerando que certas decisões de empresas geram impactos no espaço e nas vidas dos citadinos. Ele poderia implicar, na prática, a abertura de espaços para tomadas de decisões sobre implementação de qualquer projeto - público ou privado -, plano, mudança de legislação e de atividade, em um determinado lugar, tendo como perspectiva que essas decisões poderiam impactar a produção do espaço urbano.

Entretanto, Purcell (ibid.) chama a atenção para o fato de que o exercício desse direito não significa que seu resultado seja necessariamente a produção de espaços, bairros e cidades mais justas e menos desiguais, pois seu resultado sempre será condicionado pela contingência de cada momento e lugar. No entanto, o alerta de Purcell não visa constranger a luta pelo direito à participação citadina, mas propõe-se a pautar uma discussão sobre os riscos reais da sua realização.

Já o direito à apropriação consiste, nas palavras de Lefebvre (2013), na modificação do espaço por um grupo de indivíduos para servir às suas necessidades. A apropriação, seja sua atividade, seja sua definição mesma, é o que permite, aos citadinos, converter a produção do espaço urbano em obra, o mais próximo possível da concepção de obra de arte. 0 espaço apropriado também pode ser definido a partir do seu oposto, o espaço dominado, embora essa oposição não exista na realidade, senão em termos teóricos, pois ambos coexistem. 0 espaço dominado é aquele determinado pelas suas relações de propriedade e de consumo (produção para o consumo, para o lucro). No espaço capitalista, o espaço dominado impõe-se, mas não impede que apropriações aconteçam simultaneamente. 
A oposição espaço apropriado versus dominado remete a outra, também teorizada por Lefebvre, que é a oposição "valor de uso" versus "valor de troca". 0 valor de uso refere-se ao valor que os objetos e que o espaço mesmo adquirem quando são usados e/ou construídos, tendo como perspectiva a realização das necessidades dos seus habitantes. Nesse sentido, 0 que dá valor aos objetos e aos espaços é o seu uso, e, quando esses são produzidos na perspectiva do uso, segundo Lefebvre, podemos dizer que são de fato apropriados. E, mais do que isso, "é sobretudo o uso político do espaço que restitui ao máximo o valor de uso: recursos, situações espaciais e estratégias" (ibid., p. 389; tradução nossa). Já o valor de troca condiciona o uso e a produção dos objetos e do espaço a uma relação monetária, visando ao lucro e estimulando o consumo - assim são pensados, produzidos e geridos os espaços dominados. É, seguindo esse raciocínio, que Purcell, a partir de Lefebvre, afirma que:

Não só é apropriação o direito de ocupar o espaço urbano já produzido, mas também o direito de produzir espaço urbano para que esse atenda às necessidades dos habitantes. Porque a apropriação dá aos habitantes o direito ao "uso total e completo" do espaço urbano no decorrer da vida cotidiana. (Purcell, 2002, p. 103, tradução nossa)

Sobre a utilização do conceito de direito à cidade na América Latina, Purcell (2013) chama a atenção para a redução da sua potência às pautas de reivindicação de políticas e planos setoriais que, na prática, pouco tinham de revolucionários, nos termos definidos por Lefebvre. Segundo o Purcell (2002), a construção teórica e utópica de Lefebvre clamava por uma reestruturação radical das relações sociais, políticas e econômicas, o que em geral não era 0 foco das pautas reformistas latino-americanas. De fato, Lefebvre propunha uma revolução na produção do espaço urbano, pautada nos direitos à participação e à apropriação.

No Brasil, o conceito de direito à cidade foi incorporado por movimentos de reforma urbana na década de 1980 e tinha como pressupostos a conquista e o acesso a serviços e infraestruturas ausentes na maioria dos bairros populares das capitais. Assim, o direito à cidade aqui faz referência muito mais ao direito à habitação, ao saneamento e a equipamentos e serviços do que à participação e à apropriação.

A pauta da Plataforma da Reforma Urbana incluía, ainda, o direito à participação na construção de políticas públicas e investimentos, e a solução construída para efetivação dessas demandas foi a criação de conselhos que foram integrados às administrações públicas das três esferas. Os conselhos relacionados ao desenvolvimento urbano ganharam corpo a partir de 2003, com a criação do Ministério das Cidades, que instituiu, por meio da Conferência Nacional das Cidades, e incorporou, à sua gestão, o incentivo à criação de conselhos municipais e estaduais. Muitas foram as críticas ao funcionamento desses conselhos, que, na prática, tiveram seu poder de decisão reduzido ao longo do tempo (Gohn, 2013, 2011a, 2011b).

Ainda assim, é preciso reconhecer que as pautas e as lutas pela reforma urbana no Brasil tinham sua reserva revolucionária, pois Lefebvre (2008) reconheceu que a reforma urbana tinha, sim, um certo alcance revolucionário. E era revolucionária, pois pretendia 
a inclusão do que ele chamou de proletários na tomada de decisões e do processo de planificação. Para ele, "a realização da sociedade urbana exige uma planificação orientada para as necessidades sociais, as necessidades da sociedade urbana" (ibid., p. 138), e a potência dessa planificação somente se realiza se a população (ou os citadinos), "junto com seus mandatários políticos", encarregarem-se da planificação.

É, nesse sentido, que podemos pensar o planejamento urbano como uma ferramenta capaz de potencializar uma inversão nas relações políticas entre citadinos e governantes, e é, com essa mirada, que enxergamos os planos de bairros elaborados pelos seus moradores como atos revolucionários, dada a radicalidade das suas tarefas de tomar para si o desafio de planejar seus futuros e produzir seus espaços. Esses planos, subversivos e insurgentes por princípio - ainda que nem sempre de maneira consciente -, configuram-se como exemplos de inversão das relações sociais, políticas e econômicas e da transformação da estrutura política de poder de cada lugar.

Os casos apresentados a seguir são experiências de planejamento insurgente, desenrolados em contextos distintos e com estratégias similares, mas guardam a importância de terem sido demandados por seus moradores, que elaboraram seus planos de bairro a despeito do Estado e com o principal objetivo de participar da produção do espaço urbano e se instrumentalizar para as disputas com seus antagonistas.

\section{Planos de bairro insurgentes}

\section{Plano de bairro de Casa Amarela}

Situado na Zona Norte de Recife, o bairro de Casa Amarela possui cerca de 29 mil moradores e, embora predominantemente ocupado por uma população de classe média, parte do bairro é constituída de uma ocupação popular e se localiza vizinha à Zona Especial de Interesse Social (Zeis) Alto do Mandú/Alto Santa Izabel, e parte dessa Zeis está inserida nos seus limites administrativos. A ideia de elaboração de um plano para o bairro surgiu em 2014, após um grupo de moradores ter se unido para buscar alternativas para a redução dos assaltos frequentes no bairro, o que gerava sensação de insegurança nos seus moradores, que já não frequentavam seus espaços públicos.

Inicialmente, as soluções levantadas nas primeiras reuniões giravam em torno do aumento do policiamento no bairro e da contratação de serviço de segurança privada, o que caminhava para a construção de um "plano de paz" que chegou a ser discutido com a Secretaria de Segurança Pública do estado de Pernambuco. No entanto, nos encontros, a ideia de segurança pública começou a ser tensionada por parte dos moradores, que começou a levantar outras questões a ela relacionadas, como as mudanças nos padrões de ocupação do bairro, que se encontrava em franco processo de verticalização. Aos poucos, foram 
percebendo que o aumento de muros - em quantidade e em altura - dificultava cada vez mais a comunicação entre as áreas públicas e privadas e, por conseguinte, a interação entre os moradores, bem como o cuidado mútuo que ela possibilitava. Outro problema levantado, relacionado à falta de segurança e à redução da frequência da população moradora nas ruas, foi o aumento da velocidade e do fluxo de veículos na principal via do bairro, que foi apontado por alguns moradores como um fator também relacionado à segurança.

$\mathrm{Na}$ tentativa de dar concretude às discussões, foram criados grupos no Facebook e WhatsApp que ampliaram o debate, tanto no número de moradores como na quantidade de temas e conflitos, e, em parceria com a Universidade Federal de Pernambuco (UFPE) e a Universidade Federal Rural de Pernambuco (UFRPE), ${ }^{3}$ foi elaborado um planejamento cicloviário para as vias do bairro, que resultou na implementação de uma ciclovia em uma avenida de grande fluxo de veículos. A execução do plano pela prefeitura, no entanto, não foi efetivada como o proposto pelos moradores - uma faixa inteira destinada à circulação de veículos motorizados foi transformada numa grande ciclovia, o que gerou graves congestionamentos no bairro. Esse evento foi responsável por diversos conflitos que, ao invés de responsabilizarem a prefeitura pela má execução da proposta, culparam os moradores e sua demanda por ciclovias no bairro.

A parceria com a UFRPE também foi responsável pela tomada de conhecimento dos moradores de uma intervenção viária da prefeitura no bairro, que alteraria o sentido de uma via local, passando a ter apenas um sentido, o que, na opinião dos moradores, iria contribuir para aumentar ainda mais a velocidade dos carros e a sensação de insegurança no bairro. Após protestos e sua repercussão na mídia, a prefeitura retirou a proposta de intervenção no sentido da via.

Com isso, os moradores sentiram a necessidade de ampliar as discussões no bairro e fazerem " algo mais planejado, abrir mais, discutir mais com os vizinhos, ver o que os vizinhos vão achar", ${ }^{4}$ e, assim, surgiu a proposta do plano de bairro, sugerido em uma das reuniões. Foram, então, construídas oficinas "para discutir o que seria bom para o bairro, o que os moradores achavam bom para o bairro", que foi dividido em diferentes áreas para a realização de reuniões, nas quais se podia falar da sua localidade e do bairro como um todo. Foram definidas 43 propostas distribuídas em diversos temas e que são o horizonte de ações por meIhoria do bairro pelos seus moradores.

A participação de urbanistas e da universidade no plano bairro de Casa Amarela, segundo Vandson, não era regular e nem institucionalizada -, com exceção do arquiteto e urbanista César Barros, que participou mais ativamente da proposta das "ciclofrescas", mas isso antes de se vincular à UFRPE. Havia urbanistas moradores do bairro que participavam sazonalmente das ações e do processo de planejamento, sugerindo metodologias, compartilhando outras experiências, aproximando as gramáticas dos moradores com a do urbanismo e dando forma a algumas propostas. 0 plano de bairro não foi efetivado na sua totalidade, pois a maioria das propostas envolvia a participação dos poderes públicos, que ainda não as haviam acolhido. A movimentação dos moradores, no entanto, gerou algumas ações autogestionadas, a exemplo da criação de uma 
horta comunitária, e também intervenções da prefeitura no bairro, como a reabertura de uma biblioteca, fechada há muito tempo e sem previsão de funcionamento; a própria implantação de ciclovias e a criação de um conselho tripartite (entidades, moradores e prefeitura) para discussão e deliberação de assuntos relacionados à Casa Amarela, prevendo a participação da prefeitura que, no entanto, nunca encaminhou as questões e prioridades discutidas.

0 processo de formação pelo qual passaram aqueles que participaram das ações e da elaboração do plano de bairro assim como as ações encaminhadas pelos próprios moradores, entretanto, são conquistas que permanecem e subsidiam ações e demandas futuras dos seus moradores.

\section{Plano de bairro 2 de Julho}

0 Plano de bairro 2 de Julho também foi iniciado em 2014, como projeto de extensão universitária do grupo de pesquisa Lugar Comum, da Faculdade de Arquitetura da Universidade Federal da Bahia (FA-UFBA), a partir da demanda de moradores, organizados em um movimento de bairro chamado "Movimento Nosso Bairro é 2 de Julho" (MNB2J). 0 MNB2J já tinha dado início, em 2012, a um processo de planejamento popular, com a aplicação de um questionário para conhecer a opinião dos moradores sobre os problemas do bairro - e seus desejos para ele. 0 processo, porém, foi interrompido por dificuldades dos integrantes do MNB2J em seguir com sua execução.

Naquele momento, o 2 de Julho também se encontrava em conflito: (1) com o poder público municipal, pela ameaça de implantação de um plano de revitalização, voltada para a viabilização e valorização de investimentos imobiliários com projetos aprovados para a área e pela vedação à participação dos moradores no projeto; e (2) com empresários e especuladores imobiliários. 0 plano de bairro aparece nesse contexto como uma estratégia dos moradores na luta de resistência e pela participação da sua construção coletiva.

0 bairro 2 de Julho possui uma ocupação antiga e está localizado no Centro Antigo de Salvador. Composto, atualmente, por uma população em sua maioria de rendas média-baixa e baixa, o bairro começa a ser objeto de interesse de empresas imobiliárias, que, em alguns casos, ameaçam de expulsão alguns dos seus moradores. É o caso da Construção do Cloc Marina Residence, empreendimento localizado na encosta, que é área de proteção rigorosa e vedada à construção. Também nesse contexto, os moradores da Vila Coração de Maria estão ameaçados de expulsão, desde 2010, pela Irmandade São Pedro dos Clérigos, proprietária dos imóveis da Vila. Mas o projeto de maior monta, de proposição da prefeitura municipal, foi o "Projeto de Humanização do bairro Santa Tereza", que propunha intervenções em uma considerável porção do bairro, incluindo ruas, largos e imóveis vazios.

Essa proposta de investimento do poder público vem a reboque dos projetos da iniciativa privada - investidores vinculados ao ramo do turismo, especialmente hotelaria e entretenimento, e à especulação imobiliária - com o propósito de viabilizar a realização de renda imobiliária por parte desses agentes (proprietários de imóveis e com projetos elaborados para a área). A proposta articulava-se, ainda, com o interesse de transformação do bairro e 
da área do Centro Antigo da cidade - que possuem predominância de usos residencial e de comércio e serviços - em áreas de atividade turística, substituindo as populações existentes e as práticas cotidianas dos lugares por elas habitados e frequentados por outras, de rendas mais elevadas.

Toda essa movimentação dos setores públicos e privados em prol da renovação do bairro gerou fortes reações entre moradores e seus apoiadores que constituíram um grupo em defesa do bairro, o já citado Movimento Nosso Bairro é 2 de Julho (MNB2J), e engendraram diversas ações de resistência, dando visibilidade aos projetos públicos e privados, que não previam ações para permanência dos moradores. Dentre as ações promovidas pelo MNB2J, estão a promoção de debates públicos sobre esses temas e sobre o futuro do bairro e do Centro Antigo, além da articulação com outros agentes - Ministério Público da Bahia, Defensoria Pública da Bahia, universidades, assessorias técnicas e outros movimentos e entidades da cidade - para discutir e disputar o planejamento e projetos na escala municipal que afetam o bairro direta ou indiretamente. Essas mobilizações e articulações conseguiram que o projeto fosse oficialmente retirado pela prefeitura.

Após essa vitória, no entanto, o bairro continuou a sofrer pressões dos poderes públicos e privados - estes últimos sempre se articulando com o poder público para viabilizar seus interesses - com projetos como a reforma de largos e a construção de um mercado sem participação dos moradores e com ações de expulsão dos feirantes de rua; a construção de um teleférico na ladeira da Preguiça - cuja proposta incluía demolição de casas e expulsão de moradores -; e a criação de um Fundo de Investimento Imobiliário, que pretendia investir recursos do governo do estado para promover a financeirização da especulação imobiliária no bairro.

Nesse contexto, por demanda do MNB2J e em parceria com a Faculdade de Arquitetura da Universidade Federal da Bahia, foi elaborado o Plano de Bairro para o 2 de Julho, como proposta de elaboração colaborativa que uniria interesses de melhoria das condições de vida do bairro com o fortalecimento dos moradores, entidades e movimentos sociais, bem como dos laços entre o MNB2J e o grupo Lugar Comum da UFBA.

0 plano desenvolveu-se ao longo de 3 anos, tendo a sua última oficina ocorrido em dezembro de 2016. Um total de 20 oficinas de bairro foram realizadas com a participação de moradores, entidades, movimentos sociais e estudantes da universidade. Além das oficinas, 0 plano embasou-se numa leitura técnico-comunitária do bairro que incluiu diversas formas de coleta e análise de dados (entrevistas com 174 residentes, fichas técnicas aplicadas no bairro, análise de documentos de órgãos do governo, etc.) para conhecer e entender os principais problemas e potencialidades do bairro. 0 plano resultou na elaboração de um total de 43 propostas coletivas categorizadas em dez temáticas diferentes. ${ }^{5}$ As propostas abarcavam temas urgentes para o bairro, como a garantia de permanência dos moradores, produção e melhoria habitacional e coleta de resíduos sólidos, mas também outros temas importantes - não tão urgentes - e cuja implementação independia da ação dos poderes públicos, como a criação de uma rede de articulação entre grupos culturais e um projeto para florir o bairro. 
A participação da UFBA na elaboração do Plano de Bairro 2 de Julho teve contornos distintos da experiência de Casa Amarela, pois a universidade - que institucionalizou sua parceria com o bairro, por meio de um projeto de extensão financiado pelo Ministério de Educação e Ministério das Cidades - tomou para si a responsabilidade de elaboração do plano, assumindo funções de facilitação, mobilização e até de ativista em diversos momentos. Os moldes dessa parceria contribuíram para maior elaboração das propostas e também para um uso variado de linguagens, como a construção de uma maquete virtual para ocupação de um vazio no bairro e um vídeo sobre as memórias dos moradores.

0 plano foi entremeado (e também sucedido) por atividades de assessoria técnica e política aos moradores em questões consideradas críticas, como, por exemplo, a ameaça de fechamento do posto de saúde localizado no bairro, os decretos de desapropriação e ameaça de expulsão de moradores, bem como, após a conclusão das atividades do Plano de Bairro, a inclusão do 2 de Julho como bairro na "Lei de bairros" de Salvador.

\section{Planejamento insurgente e direito à cidade: uma perspectiva desde/para o Sul global}

As práticas de planejamento de bairro apresentadas acima emergem de conflitos e da convergência de citadinos e coletivos com experiências múltiplas e do desejo de construir outras formas de pensar e agir sobre o bairro, inspirado em princípios que visam a garantir o "direito à cidade", na forma conceituada por Henri Lefebvre. Assim, nessas duas experiências de elaboração de plano de bairro, a luta pelo direito à cidade constituiu-se como parte integrante do caráter insurgente do planejamento. A análise desses casos revela algumas semeIhanças e diferenças na maneira de reivindicar o direito à cidade como forma de planejamento insurgente, seja nas práticas simbólicas e materiais performadas de modo implícito ou explícito, seja nos instrumentos usados, formal ou informalmente, com suas tensões, intenções e finalidades, seja, ainda, na constituição de sujeitos e de subjetividades insurgentes.

Na perspectiva dos planos de bairro de Casa Amarela e do 2 de Julho, o planejamento insurgente iniciou-se com questionamentos sobre a própria constituição dos pesquisadores/ estudantes - reunindo experiências de urbanistas, advogados, arquitetos, historiadores, geógrafos, firmando os pés na militância e na academia, juntando-se e misturando-se com lideranças do bairro -, artistas (no caso do 2 de Julho) e representantes de associações e de diferentes segmentos sociais. Passou, também, pela transformação desses agentes em planejadores urbanos.

No bairro 2 de Julho, o direito à cidade foi reivindicado por esses protagonistas de forma explícita nos discursos usados ao longo da elaboração do plano para explicitar a dimensão subversiva do processo de planejamento proposto. A performatividade discursiva do direito à cidade ao longo do processo de planejamento decorreu, de maneira significativa, do papel predominante da universidade que se constituiu, a pedido do MNB2J, como "responsável" para a efetivação do Plano de 
Bairro 2 de Julho (PB2J). Outro fator importante na adoção e no uso dessa linguagem acadêmica foi o fato de o MNB2J ser constituído em parte por pessoas de classe média, a maioria com diplomas de pós-graduação, e, portanto, já familiarizadas com a linguagem acadêmica, de forma geral, e com o conceito de direito à cidade, de forma particular. Assim, tanto a equipe universitária do PB2J quanto os integrantes do MNB2 ${ }^{6}$ foram promovendo o uso discursivo do direito à cidade como ferramenta política para explicitar o propósito subversivo do planejamento e na tentativa de diferenciá-lo do planejamento "participativo" proposto pelo Estado neoliberal.

No 2 de Julho, o direito à cidade foi reivindicado no contexto do PB2J não apenas como posicionamento político e ideológico orientador das práticas construtivas de elaboração de propostas para o bairro, mas, também, como instrumento conceitual utilizado de forma reativa, nas práticas de resistência contra ações gentrificadoras pontuais dos governos municipal e estadual, que impactaram o bairro ao longo dos três anos de elaboração do plano.

Essas ações construtivas e reativas, apoiadas e orientadas pelos princípios do direito à cidade, foram realizadas por vias tanto formais/ institucionais (relatórios, pareceres, assembleias, etc.) quanto informais (manifestações nos espaços públicos, encontros e oficinas, divulgação de informação nas redes sociais, etc.), na intenção de dialogar, pressionar ou denunciar as ações antidemocráticas do Estado e de construir propostas alternativas para o bairro. Nas vias formais, o conceito do direito à cidade foi frequentemente instrumentalizado com base na sua dimensão legal, interpelando-se a Constituição Federal de 1988 e o Estatuto da Cidade de 2001.
No caso do bairro da Casa Amarela, a associação de moradores também reivindicou o direito à cidade na elaboração de propostas que permitissem, aos moradores, reapropriarem-se das ruas e dos espaços públicos do seu bairro (por exemplo, através de reestruturações viárias) como forma de aumentar sua segurança, sem o uso de medidas repressivas (policiamento), na tentativa de garantir que o bairro permanecesse acessível e seguro para todos. Nesse caso, o direito à cidade foi reivindicado não de forma explícita, no uso do conceito nos discursos dos planejadores insurgentes, mas em propostas que promoviam o direito de acesso, de uso e de apropriação do espaço urbano, como a criação da horta, a reabertura da biblioteca e a implantação de ciclovias; e também pelo exercício do direito à participação no planejamento do seu bairro e da cidade.

Percebemos, nos dois casos, que a luta pelo direito à cidade e o planejamento insurgente vão se constituindo mutuamente. A articulação entre esses dois conceitos pode parecer incoerente, já que o direito à cidade tem sido criticado por militantes e acadêmicos por ter sido demasiadamente institucionalizado ou despolitizado, apresentando características cada vez mais reformistas e menos transformadoras (Souza, 2010). Em contraste, o planejamento insurgente coloca-se explicitamente como fora do ou contra o Estado e, nesse sentido, afirma sua dimensão subversiva de forma mais contundente.

Porém, nos nossos estudos de caso, 0 direito à cidade revela-se insurgente porque emerge num contexto político de perda crescente da legitimidade do Estado e das suas instituições, particularmente no que diz respeito ao Estado de Direito. Isto tem se manifestado, 
na cidade, por um estado permanente de exceção, em que o desrespeito à lei se torna regra (Vainer, 2011, p. 7), fazendo com que as leis instituídas a partir da Constituição de 1988, como resultado de uma longa luta social decorrente do período de redemocratização do País, não sejam aplicadas ou sejam interpretadas de forma a perpetuar as profundas desigualdades e injustiças sociais que caracterizam este País.

Nesse contexto, e como argumentado por Manzi et al. (2018), a reivindicação para que 0 direito à cidade seja efetivado se torna subversiva e insurgente e não meramente reformista - já que coloca o Estado numa posição de ilegalidade perante os citadinos, invertendo, assim, a lógica de o Estado atribuir a ilegalidade aos citadinos que ocupam o espaço urbano de forma irregular pela falta de planejamento e de políticas urbanas adequadas (Holston, 1998; Earle, 2012).

É possível perceber que as noções de "epistemologia da multiplicidade" (Sandercock, 2010) e as experiências que iluminam comunidades diversas, utilizando-se de múltiplas linguagens, vêm sendo exercidas na parceria entre pesquisadores, movimentos, organizações e moradores, constituindo-se como processo dinâmico, sempre em fazimento, que reafirma o seu caráter insurgente. A luta pelo direito à cidade via planejamento insurgente (e vice-versa), nas duas experiências, caracterizou-se pela produção de novas formas de linguagem, na busca por esses direitos junto ao poder público e por mobilizar e conscientizar a população acerca dessas problemáticas.

No caso do 2 de Julho, o processo de planejamento constituiu-se através de oficinas de bairro, nas quais várias novas linguagens foram experimentadas, tanto com o objetivo de efetivar o diálogo interno entre os planejadores insurgentes, como na busca por ampliar o diálogo e a mobilização da população dentro e fora dos limites do bairro. Usou-se da videografia e da cartografia social para evidenciar as memórias e os desejos dos moradores sobre/para o seu bairro, assim como para evidenciar os conflitos entre agentes com interesses e formas antagonistas de pensar e produzir a cidade. Por exemplo, a leitura técnico-comunitária, realizada no primeiro e segundo ano de elaboração do Plano, revelou mais de 80 terrenos vazios e subutilizados. A partir dessa constatação, a equipe do PB2J, em colaboração com o MNB2J, organizou oficinas de cartografia social cujo objetivo principal era elaborar propostas coletivas para alguns desses terrenos vazios, para que voltassem a cumprir as suas funções sociais.

No Brasil, a função social da propriedade e da cidade é um direito constitucional, e foi esse direito à cidade que os residentes do 2 de Julho reivindicaram através da cartografia social. Várias formas de cartografia social foram experimentadas ao longo desse processo (sensorial, desenhos, GIS, modelagem). 0 resultado final foi apresentado através de uma modelagem 3D com o uso do software SketchUp. A ideia era usar uma linguagem que pudesse dialogar com o poder público para aumentar a possibilidade de as propostas serem contempladas por ele. Ou seja, foi proposto o uso de uma linguagem hegemônica - o uso de tecnologias comumente utilizadas em projetos urbanos desenhados pelo governo ou pela iniciativa privada, tais como o GIS e a modelagem - de forma estratégica, para fins subversivos. Esse tipo de estratégia tem sido amplamente usada por movimentos identitários que reivindicam 
seus direitos através do que Spivak (1990) chamou de "essencialismo estratégico", um processo performativo em que grupos subalternos (por exemplo, movimentos feministas, negros e indígenas) se apropriam de termos e categorias criadas pelos seus opressores para exigir seus direitos.

No caso do Plano da Casa Amarela, o apelo à linguagem técnica dos urbanistas e acadêmicos também teve papel central na busca por abrir um espaço de diálogo com o poder público para que a população do bairro pudesse pautar e legitimar as suas demandas. Nesse caso, a associação de moradores do bairro, em conjunto com urbanistas, elaborou propostas de intervenção usando os instrumentos de planejamento urbano, tais como a criação de um conselho de bairro paritário entre moradores e prefeitura; de um plano específico para as zonas especiais de desenvolvimento Econômico do bairro; e de um plano de mobilidade local sustentável e de acessibilidade.

Assim, nos dois casos, houve uma troca importante de saberes entre vários sujeitos de conhecimento. Apesar de a equipe de urbanistas/acadêmicos estar atenta e consciente da importância de desestabilizar a relação de poder entre o conhecimento técnico e leigo, o caráter subversivo e insurgente do planejamento exigiu usar o "poder/conhecimento" (Foucault, 1980) de forma estratégica para tornar o plano de bairro um instrumento de reivindicação efetivo, especialmente perante 0 poder público, de modo a aumentar as possibilidades de competir - ainda que dentro de um campo de forças muito desigual - com os planos de revitalização de interesse do setor privado e, assim, contribuir com a luta pelo direito à cidade.
Dessa maneira, concordamos com Vainer et al. (2013, p. 17) quando defende que 0 "direito à cidade, nessa perspectiva, se afirma como direito a pensar e lutar por uma cidade diferente, cujos destinos sejam definidos por outros que não aqueles que fazem da cidade um grande negócio". Além disso, a troca de conhecimento possibilitada pelo processo de elaboração coletiva das propostas dos dois planos de bairro contribuiu para a democratização do conhecimento acadêmico e para a valorização de outros tipos de conhecimento.

Em termos de implicações e resultados desses planejamentos insurgentes, nos dois casos, as propostas de intervenção urbana não foram acolhidas pelo poder público. Para o 2 de Julho, isso não impediu que os resultados preliminares fossem usados em algumas das suas demandas. ${ }^{7}$ Para a Casa Amarela, as propostas simplesmente não foram contempladas pelo poder público, apesar de terem sido formalmente apresentadas a ele. No entanto, essas experiências mostram como o planejamento insurgente se revela enquanto conquista mais como processo do que como resultado concreto ou imediato. As maiores conquistas nos dois casos foram a transgressão, o deslocamento e a transmutação que essas experiências proporcionaram para os sujeitos envolvidos.

Esses processos contribuíram para fortalecer as relações entre moradores e entidades dos bairros, movimentos e universidade; conscientizar suas populações sobre a importância de entender o direito à cidade na sua dimensão coletiva e não individual; e produzir novas subjetividades insurgentes com novos instrumentos, estratégias, práticas e formas de pensar e produzir a cidade, permitindo uma (re) apropriação do espaço urbano pelos citadinos 
de forma mais concreta, cotidiana e autônoma. Como apontado por Miraftab (2009), o planejamento insurgente não se define por um ator específico (planejador), mas sim por um conjunto de práticas contestatórias, enraizadas na base, que criam seus próprios termos de engajamento.

Assim, é possível afirmar, a partir dos dois casos analisados, que a luta pelo direito à cidade pode ser entendida como parte constitutiva do planejamento insurgente e vice-versa. A nossa proposta de articular o direito à cidade com o planejamento insurgente nos ajuda, não só a "preservar o caráter radical do conceito de direito à cidade" (Latendresse e Manzi,
2018, pp. 249-250), mas também a ampliar a compreensão sobre o planejamento insurgente, desde o Sul, que vai além de uma concepção dicotômica entre Estado e sociedade. Mostra como é possível manter a dimensão subversiva do planejamento insurgente com um leque de táticas e estratégias que envolvem a possibilidade de uma relação com o Estado, suas instituições e suas linguagens, contribuindo para subverter a ordem vigente. 0 direito à cidade pensado no seu sentido original e mais radical como forma de (re)apropriação do espaço urbano também reforça o caráter não apenas reativo, mas também construtivo, criativo e transformador do planejamento insurgente.

\section{[I] https://orcid.org/0000-0001-5985-528X}

Centro Universitário Ruy Barbosa Wyden, Curso de Arquitetura e Urbanismo. Salvador, BA/Brasil. Universidade Federal da Bahia, Faculdade de Arquitetura, Programa de Pós-Graduação em Arquitetura e Urbanismo. Salvador, BA/Brasil.

thaisreboucas@gmail.com

\section{[II] https://orcid.org/0000-0001-9357-3964}

Universidade Católica do Salvador, Pró-Reitoria de Pesquisa e Pós-Graduação, Programa de Pós-Graduação em Planejamento Territorial e Desenvolvimento Social. Salvador, BA/Brasil. Maria Sibylla Merian Centre Conviviality-Inequality in Latin America. São Paulo, SP/Brasil. mayamanzi@gmail.com

\section{[III] https://orcid.org/0000-0003-4175-0089}

Universidade Católica do Salvador, Pró-Reitoria de Pesquisa e Pós-Graduação, Programa de Pós-Graduação em Planejamento Territorial e Desenvolvimento Social. Salvador, BA/Brasil. mourad.laila7@gmail.com 


\section{Notas}

(1) No caso do 2 de Julho, as autoras deste artigo participaram da sua elaboração no âmbito da Universidade Federal da Bahia, entre os anos de 2014 e 2017. Além das observações como participantes, foram consultados relatórios e sínteses da leitura técnica e comunitária do plano, bem como do processo de elaboração de propostas, estas últimas realizadas em novembro e dezembro de 2017.

(2) As análises sobre o Plano de Bairro de Casa Amarela foram feitas com base em: (1) entrevista com Vandson José de Holanda, integrante do Instituto Casa Amarela Saudável e Sustentável (Icass); (2) notícias de revistas e jornais; (3) publicações do Icass na sua página do Facebook; e (4) as propostas do plano enviadas por Vandson para as autoras.

(3) É importante destacar que a participação da UFPE e da UFRPE se deu por iniciativa de professores - Adriana Falangola Bezerra e Cesar Barros, respectivamente - que se aproximaram do bairro a partir das discussões realizadas pelos moradores.

(4) Entrevista concedida por Vandson José de Holanda, em 17 de novembro de 2018, via WhatsApp.

(5) (1) Educação e saúde; (2) Combate à desigualdade e exclusão social; (3) Mobilidade e transporte; (4) Infraestrutura, saneamento e meio ambiente; (5) Habitação; (6) Segurança pública; (7) Cultura e arte; (8) Lazer e esporte; (9) Espaços públicos e verdes; (10) Preservação do patrimônio.

(6) Importante ressaltar que alguns integrantes do MNB2J também faziam/fazem parte do grupo de pesquisa Lugar Comum e, portanto, tinham uma tripla identidade (morador/a, militante, acadêmico/a), o que ajudou a quebrar as fronteiras entre essas categorias.

(7) Como o pedido da inserção administrativa do território do 2 de Julho como bairro e a manifestação contra a venda em leilão de um terreno vazio do 2 de Julho, com o uso da modelagem 3D da proposta coletiva em vídeo e postagens de divulgação da manifestação nas redes sociais.

\section{Referências}

BEARD, V. A. (2003). Learning radical planning: The power of collective action. Planning Theory, v. 2, n. 1 , pp. 13-35.

EARLE, L. (2012). From insurgent to transgressive citizenship: housing, social movements and the politics of rights in São Paulo. Journal of Latin American Studies, v. 44, n. 1, pp. 97-126.

FERNANDES, A. (2011). Projeto "Bairros na metrópole: uma escala de política, de direito e de experiência", em desenvolvimento na Faculdade de Arquitetura no Programa de Pós-Graduação em Arquitetura e Urbanismo/PPGAU/FAUFBA, no âmbito do Programa Nacional de Pós-Doutorado/ Capes (2012-2014). Salvador.

(2013). "Decifra-me ou te devoro: Urbanismo corporativo, cidade-fragmento e dilemas da prática do Urbanismo no Brasil." In: GONZALES, S. F. N., FRANCISCONE, J. G. e PAVIANI, A. (orgs.) (2013). Planejamento e urbanismo na atualidade brasileira: objeto, teoria, prática. São Paulo, Livre Expressão. 
FERNANDES, A. e CHAGAS, M. (orgs.) (2018). O direito à cidade na França e no Brasil: uma nova agenda urbana? questões para um debate necessário e fecundo. Diálogos França-Brasil 4. Salvador, Universidade Federal da Bahia.

FOUCAULT, M. (1980). Power/knowledge: selected interviews and other writings, 1972-1977. Nova York, Pantheon.

(1995). "O sujeito e o poder". In: DREYFUS, H. e RABINOW, P. Michel Foucault, uma trajetória filosófica: para além do estruturalismo e da hermenêutica. Rio de Janeiro, Forense Universitária.

FRIEDMANN, J. (1987). Planning in the public domain: from knowledge to action. Princeton, Princeton University Press.

GOHN, M. da G. (2011a). Movimentos sociais na contemporaneidade. Revista Brasileira de Educação, v. 16, n. 47 , pp. $333-513$.

(2011b). Participação de representantes da sociedade civil na esfera pública na América Latina. Política \& Sociedade, v. 10, n. 18, pp. 223-244.

(2013). Desafios dos movimentos sociais hoje no Brasil. SER social. Brasília, v. 15, n. 33, pp. 261-384.

HARVEY, D. (2014). Cidades rebeldes: do direito à cidade à revolução urbana. São Paulo, Martins Fontes.

HOLSTON, J. (1998). "Spaces of Insurgent Citizenship". In: SANDERCOCK, L. (org.). Making the invisible visible: A multicultural planning history. Berkeley, University of California Press.

(2013). Cidadania insurgente: disjunções da democracia e da modernidade no Brasil. São Paulo, Companhia das Letras.

IRAZABAL, C. e NEVILE, J. (2007). Neighbourhoods in the lead: grassroots planning for social transformation in post-Katrina New Orleans? Planning Practice \& Research, v. 22, n. 2, pp. 131-153.

LATENDRESSE, A. e MANZI, M. (2018). “Planejamento insurgente e direito à cidade: um olhar cruzado entre as experiências de planejamento de bairro de Montreal e Salvador". In: FERNANDES, A. e CHAGAS, M. (orgs.). O direito à cidade na França e no Brasil: uma nova agenda urbana? questões para um debate necessário e fecundo. Diálogos França-Brasil 4. Salvador, Universidade Federal da Bahia.

LEFEBVRE, H. (2008). O direito à cidade. São Paulo, Centauro.

(2013). La producción del espacio. Madrid, España, Capitán Swing.

MANZI, M.; FIGUEIREDO, G. C. S.; MOURAD, L. N. e REBOUÇAS, T. M. (2018). Neighbourhood planning and the right to the city: confronting neoliberal state urban practices in Salvador, Brazil. International Journal of Urban Sustainable Development, v. 10, n. 1, pp. 1-15.

MARICATO, E. (2011). Brasil, cidades: alternativas para a crise urbana. Petrópolis, Vozes.

METH, P. (2010). Unsettling insurgency: reflections on women's insurgent practices in South Africa. Planning theory \& practice, v. 11, n. 2, pp. 241-263.

MIRAFTAB, F. (2009). Insurgent planning: situating radical planning in the Global South. Planning Theory, v. 8, n. 1, pp. 32-50.

(2016). Insurgência, planejamento e a perspectiva de um urbanismo humano. Revista Brasileira de Estudos Urbanos e Regionais, v. 18, n. 3, pp. 363-377. 
MOURAD, L. (2012). Relatório de pesquisa: bairros na metrópole: uma escala de política, de direito e de experiência, desenvolvido no âmbito do Programa Nacional de Pós-Doutorado/CAPES, junto à Faculdade de Arquitetura no Programa de Pós-Graduação em Arquitetura e Urbanismo/PPGAU/ FAUFBA, sob a coordenação da professora doutora Ana Fernandes. Salvador, Universidade Federal da Bahia.

PURCELL, M. (2002). Excavating Lefebvre: The right to the city and its urban politics of the inhabitant. GeoJournal, v. 58, pp. 99-108.

(2013). Possible worlds: Henri Lefebvre and the right to the city. Journal of Urban Affairs, v. 36, n. 1, pp. 141-154.

RANDOLPH, R. (2007). Do planejamento colaborativo ao planejamento 'subversivo': reflexões sobre limitações e potencialidades de Planos Diretores no Brasil. Scripta Nova: revista electrónica de geografía y ciencias sociales, n. XI, pp. 245-272. Disponível em: http://www.ub.es/geocrit/sn/ sn-24517.htm. Acesso em: 21 fev 2019.

REBOUÇAS, T. de M. e SILVA, S. S. da (2015). Planos de bairro e participação popular em Salvador. In: SEMINÁRIO URBANISMO DA BAHIA URBA[15]. UMA NOVA AGENDA URBANA? RUMO AO HABITAT III. Anais... Salvador.

SANDERCOCK, L. (1999). Translations: from insurgent planning practices to radical planning discourses. Plurimondi, v. 1, n. 2, pp. 37-46.

(2010). From the campfire to the computer: An epistemology of multiplicity and the story turn in planning. Multimedia explorations in urban policy and planning. Springer, Dordrecht, pp. 1737.

SANTOS, C. N. F. (coord.) (1985). Quando a rua vira casa: a apropriação de espaços de uso coletivo em um centro de bairro. São Paulo, Projeto.

SANTOS, M. (2004). A natureza do espaço: técnica e tempo, razão e emoção. São Paulo, Editora da Universidade de São Paulo.

SOUZA, M. L. de. (2010). Which right to which city? In defense of political-strategic clarity. Interface, v. 2 , n. 1 , pp. 315-333.

SPIVAK, G. C. (1990). The Post-Colonial Critic: interviews, strategies, dialogues. Nova York/Londres, Routledge.

SWEET, E. L. e CHAKARS, M. (2010). Identity, culture, land, and language: stories of insurgent planning in the Republic of Buryatia, Russia. Journal of Planning Education and Research, v. 30, n. 2, pp. 198-209.

VAINER, C. et al. (2013). O Plano Popular da Vila Autódromo: uma experiência de planejamento conflitual. In: XV ENCONTRO NACIONAL DA ANPUR. Recife. Anais. Recife, Anpur. Disponível em: http://anais.anpur.org.br/index.php/anaisenanpur/article/view/168/165. Acesso em: 2 jun 2019.

VAINER, C. (2011). Cidade de exceção: reflexões a partir do Rio de Janeiro. In: XIV ENCONTRO NACIONAL DA ANPUR. Anais. Rio de Janeiro.

VILLAÇA, F. (2005). As ilusões do Plano Diretor. Disponível em: http://www.flaviovillaca.arq.br/pdf/ ilusao_pd.pdf. Acesso em: 10 jun 2012. 
WATSON, V. (2014). The case for a southern perspective in planning theory. International Journal of E-Planning Research, v. 3, n. 1, pp. 23-37.

YIFTACHEL, O. (2006). Essay: re-engaging planning theory? Towards "south-eastern" perspectives. Planning Theory, v. 5, n. 3, pp. 211-222.

Texto recebido em 15/mar/2019

Texto aprovado em 24/jun/2019 